\title{
Nitrite effect on the phosphorus uptake activity of phosphate accumulating organisms (PAOs) in pilot-scale SBR and MBR reactors
}

\author{
Gürkan Sin ${ }^{1,2 *}$ Kwinten Niville ${ }^{3}$, Giulia Bachis', Tao Jiang'1, Ingmar Nopens', Stijn van Hulle ${ }^{3}$ \\ and Peter A Vanrolleghem ${ }^{1,4}$ \\ ${ }^{1}$ BIOMATH, Department of Applied Mathematics, Biometrics and Process Control, Ghent University, Coupure Links 653, \\ B-9000 Gent, Belgium \\ ${ }^{2}$ Department of Chemical \& Biochemical Engineering, Technical University of Denmark, Building 229DK-2800 Kgs. Lyngby, Denmark \\ ${ }^{3}$ Research group EnBiChem, Department of Industrial Engineering and Technology, University College West Flanders, \\ Graaf Karel De Goedelaan 5, 8500 Kortrijk, Belgium \\ ${ }^{4}$ Professor, modelEAU, Département de génie civil, Pavillon Pouliot, Université Laval, Québec G1K 7P4, Canada
}

\begin{abstract}
Batch tests were performed to investigate the nitrite effect on the P-uptake of biomass grown in pilot-scale SBR and MBR systems. The results showed that the nitrite has an inhibitory effect on the aerobic P-uptake of the SBR and the MBR biomasses. The degree of inhibition was observed to be $65 \%$ and $37 \%$ at $10 \mathrm{mg} \mathrm{NO}-\mathrm{N} / \ell$ for the SBR and the MBR respectively. Both biomasses were found capable of using nitrite as electron acceptor as effectively as nitrate. Moreover, for the SBR biomass the anoxic P-uptake rate using nitrite was found even higher $(60 \%)$ than the P-uptake rate with nitrate. From a modelling point of view, the current models require appropriate extensions to describe these various effects of nitrite. Hence, an extension of the ASM2d model has been provided. Prevention of nitrite build-up in full-scale EBPRs will eliminate the nitrite inhibition problem. Alternatively one can adopt a proactive approach in which the aerobic P-uptake phase is replaced with an anoxic P-uptake phase using only nitrite as electron acceptor. Such an approach offers considerable cost savings and enhanced nitrogen and phosphorus removal. This, however, requires further research for experimental validation and testing.
\end{abstract}

Keywords: ASM2d, MBR, modelling, nitrogen and phosphorus removal, nitrite inhibition, polyphosphate accumulating organisms, phosphate uptake, SBR

\section{Introduction}

Microbiological investigation of the nitrite effect with a variety of physiological types of bacteria (from aerobes to facultative anaerobes) has shown that nitrite interferes with energy generation (e.g. by inhibiting oxygen uptake, oxidative phosphorylation or proton-dependent active transport of substrate) and growth mechanisms (Yarbrough et al., 1980; Rake and Eagon, 1980). In the field of activated sludge, the inhibitory effect of nitrite (its effect is mainly $\mathrm{pH}$ dependent and better represented as function of the nitrous acid concentration, $\mathrm{HNO}_{2}$ ) on the nitrifying biomass activities have also been long recognised and documented (Anthonisen et al., 1976; Van Hulle et al. (2007); Vadivelu et al., 2006). Moreover, nitrite has also been experimentally observed to inhibit the activity of ordinary aerobic heterotrophic organisms (Musvoto et al., 1999). Nitrite was also hypothesised to cause proliferation of filamentous bulking in activated sludge systems due to its interference with the aerobic respiratory mechanism (Casey et al., 1999).

Several studies with phosphorus accumulating organisms (PAOs) have also confirmed that elevated concentrations of nitrite negatively affect phosphorus uptake activities of PAOs

\footnotetext{
* To whom all correspondence should be addressed.

谓 +45 45252960; fax: +45 459329 06;

e-mail: gsi@kt.dtu.dk

Received 14 September 2007; accepted in revised form 21 December 2007.
}

under both aerobic and anoxic conditions (Meinhold et al., 1999; Saito et al., 2004). Note that denitrifying PAOs were also shown to be able to utilise nitrite as an electron acceptor without any adverse affect of course within a certain concentration range.

That said, however, these studies have reported different types of effect (e.g. inhibitory vs. toxic effect) and different threshold values of inhibition by nitrite. For example, Meinhold et al. (1999) found that a nitrite level of 6 to $8 \mathrm{mg} \mathrm{NO}-\mathrm{N} / \ell$ completely halted the anoxic P-uptake and severely inhibited aerobic P-uptake for sludge taken from a pilot BIODENIPHO ${ }^{\circledR}$ plant. Saito et al. (2004) reported that $2 \mathrm{mg} \mathrm{NO}-\mathrm{N} / \ell$ already inhibited the aerobic P-uptake severely while more than $6 \mathrm{mg}$ $\mathrm{NO}_{2}-\mathrm{N} / \ell$ completely stopped it. Moreover, they also found that nitrite at $12 \mathrm{mg} \mathrm{NO}-\mathrm{N} / \ell$ level reduced the anoxic p-uptake rate down to $65 \%$. On the other hand, Ahn et al. (2001) and Hu et al. (2003) could not find any severe effect on the anoxic P-uptake rate at elevated nitrite concentrations, even up to 40 and $35 \mathrm{mg} \mathrm{NO}-\mathrm{N} / \ell$ respectively. The varying degree of adaptation of biomass to nitrite has been offered as explanation for these wide-ranging threshold values of nitrite inhibition. Saito et al. (2004), however, argued that chemical precipitation may occur if $\mathrm{pH}$ is not controlled during batch tests, which may corroborate some of the reported results.

Since the underlying biochemical mechanism of the nitrite effect is still far from being clear, in this study, we investigated and evaluated the effect of nitrite on aerobic and anoxic phosphate uptake by PAOs enriched in nutrient removing pilot-scale 
SBR and MBR systems. The knowledge of the nitrite effect in the system was necessary for two particular reasons:

- To complement our understanding of the systems' performance

- To assist in making an appropriate choice of model structure for properly describing possible nitrite inhibition of aerobic P-uptake as well as for adequately describing the mechanism of anoxic P-uptake with nitrite and nitrate by denitrifying PAOs (see e.g. Sin et al., 2006a).

To this end, we have performed $\mathrm{pH}$ - and temperature-controlled batch experiments using sludges sampled from SBR and MBR systems respectively, where we measured and evaluated phosphorus uptake and anoxic respiration rates. The SBR and MBR systems and the experimental procedure are described, which is followed by a presentation of the results obtained. Next, the results are critically discussed in view of modelling EBPR systems and the paper ends with an engineering outlook and conclusions.

\section{Material and methods}

\section{The SBR and MBR systems}

The sludges used for batch tests were sampled from the SBR and MBR reactors. These systems were fed with synthetic wastewater, the composition of which was developed elsewhere (Boeije et al., 1999). The average concentrations of the total COD, total nitrogen, nitrate, total phosphate and suspended solids in the feed were $504 \pm 55 \mathrm{mg} \mathrm{COD} / \ell, 64 \pm 7.5 \mathrm{mg} \mathrm{N} / \ell, 3.4 \pm 1.2 \mathrm{mg} \mathrm{NO}_{3}-\mathrm{N} / \ell, 11 \pm 1.3$ $\mathrm{mg} \mathrm{P} / \ell$ and $3.3 \pm 0.1 \mathrm{mg} \mathrm{SS} / \ell$ respectively (Boeije et al., 1999).

The temperature in both reactors was controlled at $15^{\circ} \mathrm{C}$ using two identical cooling systems (WK 1400, Lauda, Germany). All other devices controlling and monitoring the SBR and MBR set-ups are connected to a LabView data acquisition and control (DAC) system (National Instruments, USA). The DAC system consists of a computer, interface cards, meters, transmitters, sensors, valves, pumps and solid-state relays. The status and the time series of the signals from the sensors are also displayed on the computer and stored in a data file to be analysed later on.

\section{The SBR set-up}

The sequencing batch reactor (SBR) has been operated for both nitrogen and phosphorus removal following an anaerobic-aero- bic-anoxic-aerobic reaction sequence. The reactor has a total volume of $80 \ell$ but only $68 \ell$ was used during the operation. The volumetric exchange rate (VER) was set to 0.5 , which corresponds to $34 \ell$ of filling volume in each cycle and a hydraulic retention time (HRT) of $12 \mathrm{~h}$. The sludge wastage rate was set to $0.5 \ell$ per cycle to ensure a $17 \mathrm{~d}$ solids retention time (SRT), but the effective SRT was lower due to solids washout in the effluent (see results). The duration of one SBR cycle was $6 \mathrm{~h}$ and comprised the following phases: $60 \mathrm{~min}$ anaerobic of which the first $20 \mathrm{~min}$ was filling; $150 \mathrm{~min}$ aerobic; $60 \mathrm{~min}$ anoxic; $30 \mathrm{~min}$ aerobic; and $60 \mathrm{~min}$ of settling/draw phases. During the aerobic phases, the oxygen is controlled at around $2 \mathrm{mg} \mathrm{O} / \ell$ using a PID controller implemented in LabView ${ }^{\circledR}$, which controls the airflow by manipulating a mass flow controller (Brooks ${ }^{\circledR}$, Brooks Instrument, USA). While a detailed description of the set-up can be found in Insel et al. (2006), the configuration is shown in Fig. 1.

\section{The MBR set-up}

The membrane bioreactor (MBR) was operated continuously (unlike the SBR) to achieve biological nitrogen and phosphorus removal. The MBR consists of an anaerobic compartment ( $8 \ell$ ), an aerobic/anoxic compartment $(17 \ell)$ and an aerobic membrane loop $(3.8 \ell)$. The influent was continuously fed at $0.075 \ell / \mathrm{min}$ rate to the anaerobic compartment (see Fig. 2). The sludge was

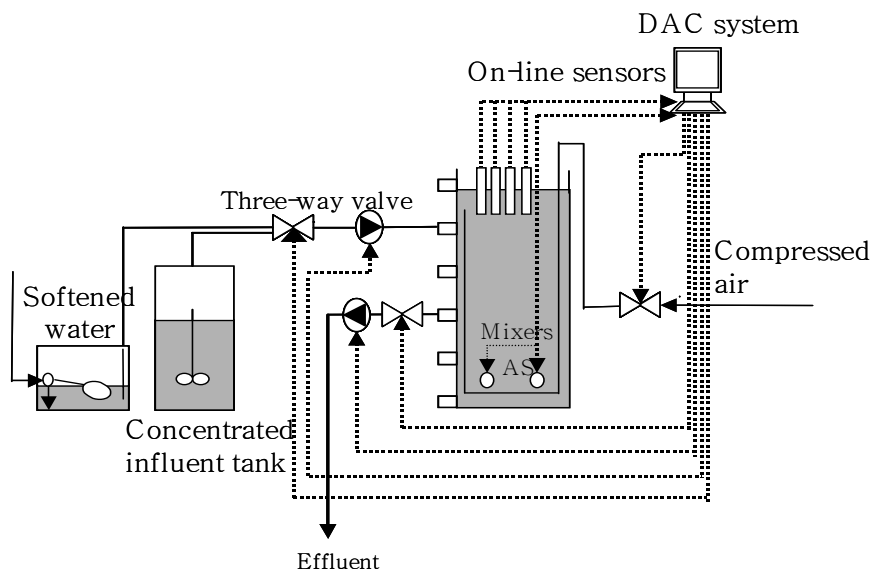

Figure 1

Schematic diagram of the SBR system (Insel et al., 2006)
Figure 2

Schematic illustration of the MBR set-up (backwashing unit is not shown, adapted from Jiang, 2007)

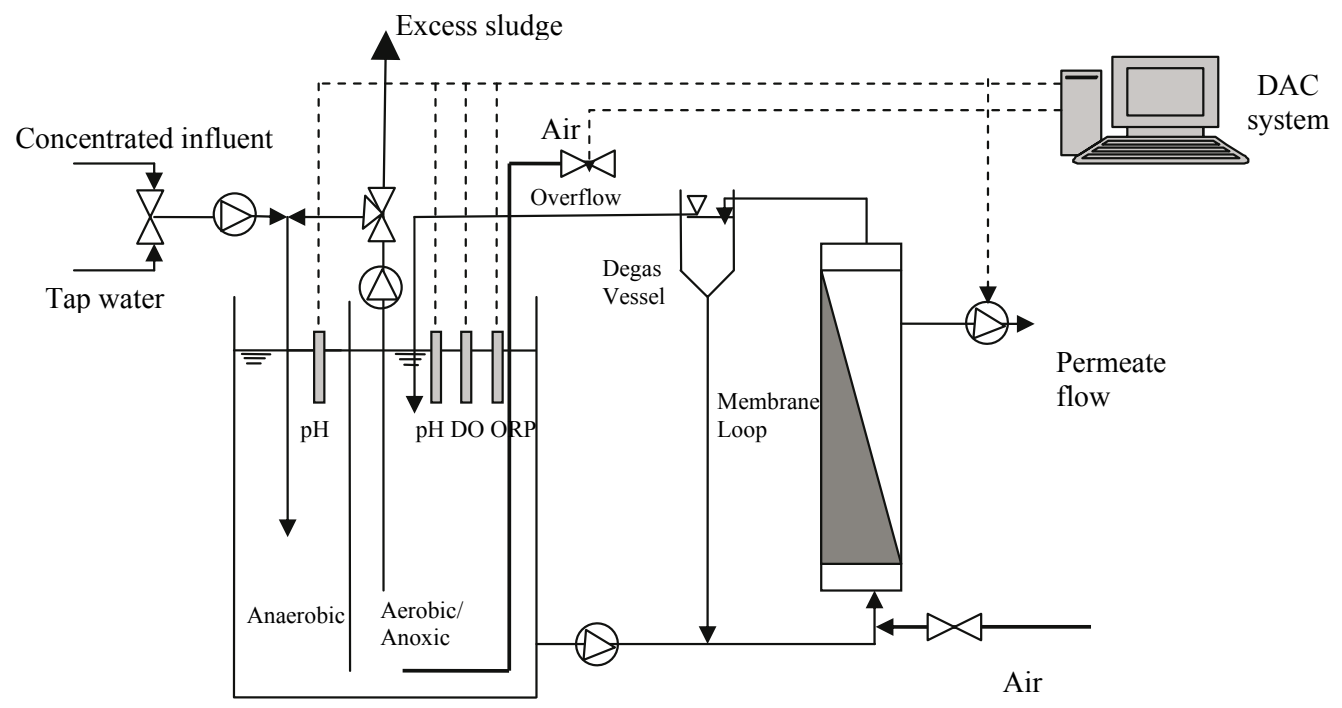

Available on website http://www.wrc.org.za 
recycled (at a rate of $0.6 \mathrm{l} / \mathrm{min}$ ) internally from the anoxic/aerobic compartment during the last $12 \mathrm{~min}$ anoxic phase (i.e. it was intermittently recycled) back to the anaerobic compartment. The anoxic/aerobic compartment was intermittently aerated following a cycle of $40 \mathrm{~min}$ of which $17 \mathrm{~min}$ was aerobic and $23 \mathrm{~min}$ was anoxic. Every $6 \mathrm{~h} 400 \mathrm{~m} \ell$ of sludge volume was wasted from the aerobic/anoxic compartment during the aerobic phase providing an SRT of $17 \mathrm{~d}$.

The solid-liquid separation was achieved using a side-stream membrane system. To this end, a tubular membrane module (X-flow UF membrane, Norrit, The Netherlands) with a $0.17 \mathrm{~m}^{2}$ surface area was used. Sludge at a flow rate of $0.375 \mathrm{l} / \mathrm{min}$ was pumped into the membrane module and the permeate flow rate was fixed to $0.09 \mathrm{l} / \mathrm{min}$ which corresponds to a constant flux of $31.8 \mathrm{l} / \mathrm{m}^{2}-\mathrm{h}$. The range of trans-membrane pressure was between 6 and $18 \mathrm{kPa}$. A more detailed description of the side-stream MBR can be found in Jiang (2007).

The aeration is controlled by using a simple on-off controller at a set-point of around $2 \mathrm{mg} \mathrm{O}_{2} / \ell$ with $0.5 \mathrm{mg} \mathrm{O}_{2} / \ell$ band. Further information about the configuration and operation of the SBR and MBR systems can be found in Insel et al. (2006) and Jiang (2007) respectively.

\section{The phosphorus release and the phosphorus uptake batch tests}

The phosphorus release and uptake tests were performed in a set-up consisting of a $2 \ell$ glass reactor with a double jacket enabling circulation of cooling liquid around the reactor for temperature control (see Fig. 3). A Lauda Ecoline E303 was used as cooling system to maintain the temperature at $15 \pm 0.1^{\circ} \mathrm{C}$. Data acquisition, $\mathrm{pH}$ control and data processing are implemented in LabView software (National Instruments, NIDAQ 6.9 with AT-MIO-16XE-50 DAQ card and LabView 6.i). The dissolved oxygen is measured by an Inpro 6100/120/T/N (Mettler Toledo) oxygen electrode, which is connected to Knick Process 73 transmitter. The $\mathrm{pH}$ is measured in the aeration vessel with a HA405-DXK-S8/120 pH electrode (Mettler Toledo), which is connected to a Knick Stratos $2401 \mathrm{pH}$ transmitter. Both electrodes were calibrated regularly (once every week). The data acquisition interval was set to $3 \mathrm{~s}$ and the $\mathrm{pH}$ was controlled within a narrow band $(7.5 \pm 0.03)$.The reactor is provided with a mixer and a tubular diffuser for supplying air or nitrogen gases as needed.

\section{Experimental procedure for the phosphorus release and uptake tests}

Aliquots of $1 \ell$ of fresh sludge samples taken daily from the SBR and the MBR systems were used for the experiments. The sludge sample from the SBR was taken at the end of the second aerobic phase (see above), while the sludge sample from the MBR was taken from the aerobic/anoxic compartment during the aerobic sub-phase of the intermittent aeration. The $\mathrm{pH}$ and the temperature were controlled at 7.5 and $15^{\circ} \mathrm{C}$ respectively during both tests. For the phosphorus release, the following procedure was followed:

- Anaerobic phase: Anaerobic conditions were reached and maintained for $75 \mathrm{~min}$, by continuously sparging nitrogen gas to the reactor.

- Addition of acetate: Small amounts of acetate (e.g. 50 to $75 \mathrm{mg}$ COD-acetate/ $\ell$ ) from a concentrated stock solution $(10 \mathrm{~g} \mathrm{COD} / \ell)$ were added to the reactor. In case there was nitrate present in the sludge liquor, additional acetate was added to ensure complete denitrification of nitrate. To this end, a stoichiometry of $6 \mathrm{mg} \mathrm{COD} / \ell$ was used to ensure a complete denitrification of $1 \mathrm{mgNO}_{3}-\mathrm{N} / \ell$. For example, if there is $5 \mathrm{mg} \mathrm{NO}-\mathrm{N} / \ell$ present in the mixed liquor of the sludge sample, additional of $30 \mathrm{mg} C O D$-acetate/ $\ell$ were added to the reactor on top of the $50 \mathrm{mg} \mathrm{COD} / \ell$.

- Sampling: Activated sludge samples of $5 \mathrm{~m} \ell$ were taken directly from the reactor using a syringe. The first sample was taken before the addition of the substrate, in order to measure the initial ortho-phosphate and nitrate concentration (see Item 2).

- Filtration: Millipore filters $(0.45 \mu \mathrm{m})$ were used immediately to filter the samples from the SBR sludge, which were immediately refrigerated at $4{ }^{\circ} \mathrm{C}$ for later analysis. To separate sludge from liquid in the MBR sludge samples, the sludge sample was centrifuged at $3000 \mathrm{r} / \mathrm{min}(1200 \mathrm{~g})$ for 4 min using a refrigerated centrifuge (Sorvall RC-5B, Du Pont Instruments), since it wasn't possible to use Millipore filters due to high solids concentration.

The phosphorus uptake tests (either aerobic or anoxic) commenced right after the anaerobic phase. For the aerobic P-uptake test, a known amount of nitrite from a stock solution with $1 \mathrm{~g} \mathrm{~N} / \ell$ was added to the reactor. Then the nitrogen gas was switched off and the aeration was switched on to provide oxygen in excess

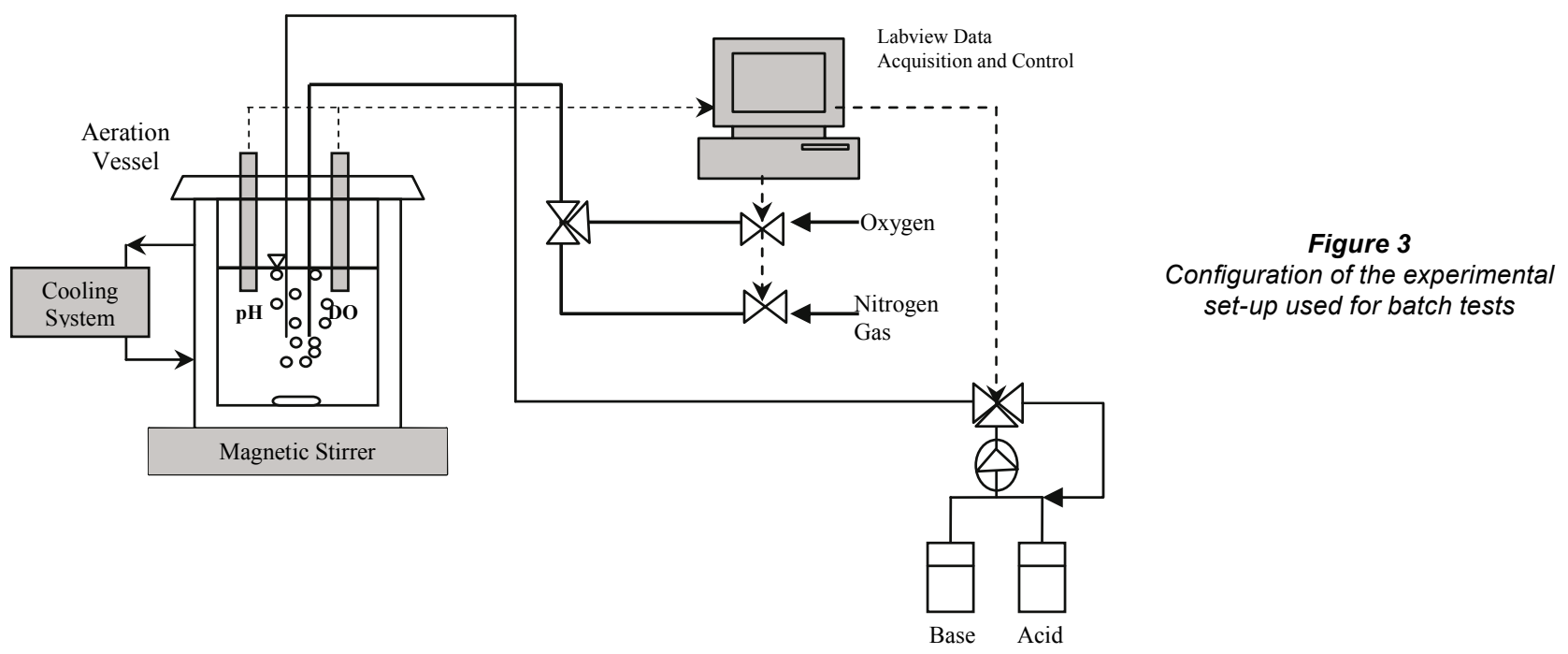


(around $9 \mathrm{mg} \mathrm{O}_{2} / \ell$ ) continuously throughout the test. For the anoxic P-uptake test, the test was started by appropriate addition of nitrite or nitrate under continuous supply of the nitrogen gas.

For the measurements of $\mathrm{COD}, \mathrm{NH}_{4}-\mathrm{N}, \mathrm{NO}_{2}-\mathrm{N}, \mathrm{NO}_{3}-\mathrm{N}$ and $\mathrm{PO}_{4}{ }^{-} \mathrm{P}$, commercial kits from HACH LANGE (Germany) were used. SVI, MLSS and MLVSS were measured according to Standard Methods (1998).

\section{Results}

\section{Monitoring the SBR and MBR systems}

In this section, off-line (daily and flow-proportionally sampled) measurements of the SBR and MBR systems are presented to provide an adequate insight into the behaviour of these systems during the batch experimental period. This is useful to assist in better interpretation of the batch results presented in the next section.

\section{The SBR system}

The average COD, nitrogen and phosphate removal percentages in the SBR were around $81 \%, 61 \%$ and $72 \%$ respectively during the experimental period. The sludge concentration time series together with sludge settling quality as monitored by SVI are shown in Fig. 4. One observes that the sludge concentration fluctuates in the reactor. Further, one also notices that starting from the beginning of June, the sludge concentration started to decrease until levelling off around $2 \mathrm{~g} / \ell$. This decrease can be attributed to the increase of the SVI.

The deterioration of the settling quality subsequently leads to more washout of the sludge in the effluent. This also means that the SRT of the system is decreased because of the higher solids washout (it was calculated to decrease from $17 \mathrm{~d}$ to ca 9 d). What induced this deterioration in the settling quality is usually a challenging task to understand. It could be due to parameters related to the process configuration/operation and or the microbiological activity, e.g. the substrate feeding pattern, $\mathrm{F} / \mathrm{M}$, nitrite at the end of aerobic phases, proliferation of filamentous organisms and the like (Sin et al., 2006b; Martins et al., 2004). A detailed discussion is, however, beyond the scope of this contribution.

Concerning the nitrogen removal, it is possible to detect a lack in nitrification from the beginning of March until mid-April (see Fig. 5 (top)). High values in the effluent ammonia concentration correspond to the absence of nitrate production, i.e. no nitrification. After this period the ammonia concentration is observed to gradually drop back to zero and at the same time the nitrate starts to increase in the effluent, as expected from the stoichiometry of the nitrification. From April onwards, one notices complete nitrification (i.e. the effluent ammonium and nitrite concentration are zero), with some sporadic events where effluent nitrite was observed to be around $1.5 \mathrm{mg} \mathrm{NO}_{2}-\mathrm{N} / \ell$, indicating incomplete nitrification. The sporadic appearance of nitrite in the effluent was mostly related to technical problems with aeration supply (e.g. pressure drop in the compressed air supply, etc.) leading to limited oxygen concentration in the reactor.

The nitrate and phosphate profiles are plotted together in Fig. 5 (bottom) to check the well-known competition between ordinary denitrifying heterotrophic organisms (DHOs) and PAOs towards VFA (in this case acetate) uptake (Manning and Irvin, 1985; Wilderer et al., 2001). The presence of nitrate during the anaerobic phase is commonly observed to slow down significantly the P-release rate of PAOs, since the presence of

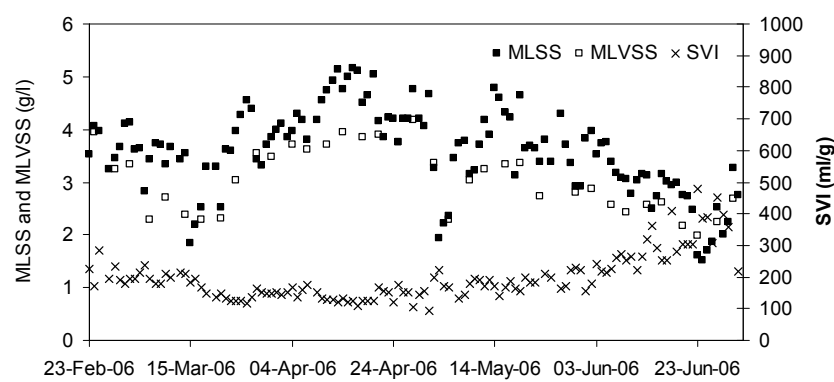

Figure 4

Time series of MLSS, MLVSS and SVI profiles in the SBR system
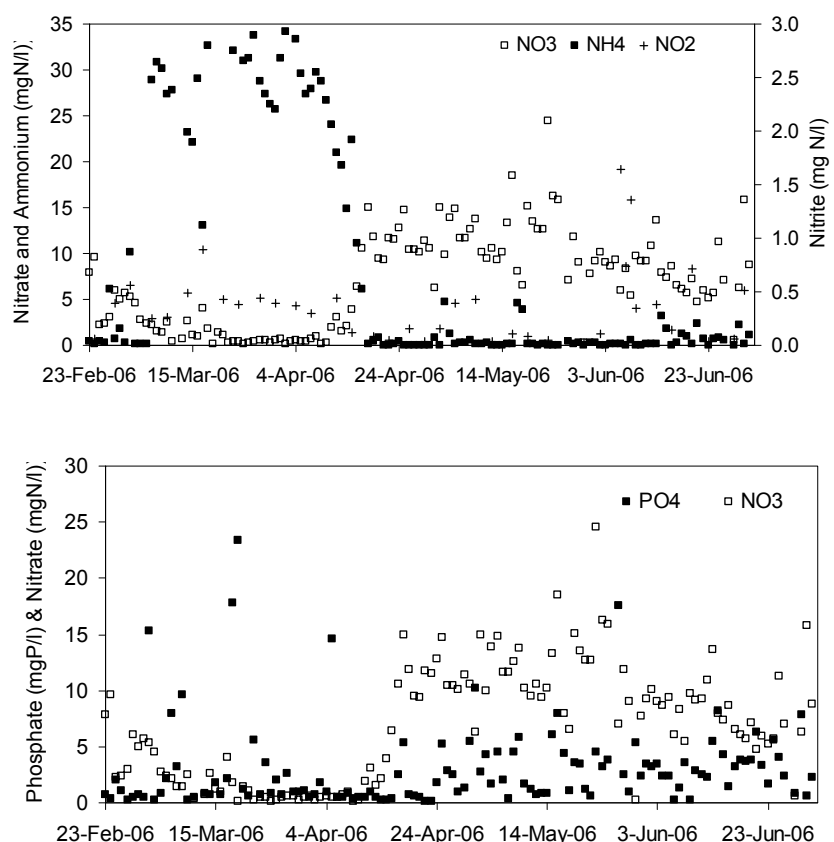

Figure 5

The effluent quality of the SBR during the experimentation period: nitrogen (top) phosphate and nitrate (bottom)

nitrate triggers denitrification by denitrifying ordinary heterotrophic organisms using VFA as the carbon source. Only after the nitrate has been completely removed from the system, the PAOs can take up acetate and release phosphate at their maximum rate. Therefore the extent of the P-release of PAOs will be determined by the extent of acetate available in the anaerobic phase which is again influenced by the amount of denitrification taking place using nitrate as electron acceptor.

From Fig. 5 (bottom), one can observe that the effluent nitrate concentration began to rise starting from the middle of April (see the explanation for the rise of nitrate in the effluent above). Parallel to the observed increase in the effluent nitrate, the effluent phosphate concentrations started to increase as well. Moreover, one can also observe fluctuations in the effluent phosphate concentration of between about 2 and $7 \mathrm{mg} P / \ell$. This indicates that the bio-P removal in the system became unstable as a result of the increased nitrate level in the anaerobic phases of the SBR.

\section{The MBR system}

The COD and nitrogen removal in the MBR are found to be around $98 \%$ and $76 \%$ respectively during the experimental period, both higher than in the SBR system, whereas the average 
phosphate removal was about $43 \%$ for the MBR, worse than for the SBR system. Further, although the COD removal was quite stable due to the almost ideal separation of the solids from the effluent (results not shown), the nitrogen and phosphate removal was not (see below).

The MLSS profile of the MBR is provided in Fig. 6. The SVI profile is absent from the figure since in the MBR system the solid-liquid separation is achieved by membrane filtration and therefore monitoring the quality of sludge settling is not required. Clearly detectable is an increase of around 50\% in the MLSS in the final part of the figure, starting from the beginning of May, in which the average MLSS was around $6 \mathrm{~g} \mathrm{SS} / \ell$, and lasting until the end of June, in which the MLSS was around $9 \mathrm{~g} \mathrm{SS} / \ell$. This increase in the MLSS was induced by a change of the influent feeding system. This change resulted in an increase in the influent load (flow rate remained fixed, but the concentration of the wastewater was higher). This in turn meant a higher amount of sludge production and therefore an increase in the MLSS concentration since the sludge wastage rate remained constant during these periods (see the line in Fig. 6).

Figure 7 (top) illustrates the effluent ammonia, nitrate and nitrite time series. Incomplete nitrification can be deduced from the higher nitrite values (up to $5.23 \mathrm{mg} / \ell$ ) appearing in the effluent from March until April. In general the effluent nitrite was observed to fluctuate periodically from a low level (around $0 \mathrm{mg}$ $\mathrm{N} / \ell$ ), indicating complete nitrification, to levels higher than $1 \mathrm{mg}$ $\mathrm{N} / \ell$ indicating incomplete nitrification. Higher values of nitrate in the effluent can be observed in the middle of April, confirming a complete nitrification process, as also indicated by the ammonia and nitrite effluent values, which are close to zero in the same period.

In Fig. 7 (bottom), one can observe that the effluent phosphate was fluctuating at around $5 \mathrm{mg} \mathrm{P} / \ell$ from February onwards till the mid of April. Afterwards, the phosphate concentration increased almost to the influent level indicating a complete loss of P-removal from the system. The P-removal was observed to recover starting from the middle of May onwards. However, the P-uptake was not sufficient to completely remove the influent phosphate, most likely due to competition with the ordinary DHOs for the limited VFAs in the influent as explained above.

It is noted that during the period when the influent load (concentration-wise) was increased (see above discussion concerning the MLSS increase in Fig. 6), the nitrate concentrations were slightly decreased and became stable (see Fig. 7 top). This is contrary to what one would have expected, namely that an increase in the influent load would cause an increase in the effluent of the system. What causes the effluent nitrate concentration to decrease is probably related to an overall improvement of the denitrification capacity of the system. On the other hand, the effluent phosphate was observed to be slightly higher during this period (Fig. 7 bottom). These observations confirm again that activated sludge systems respond in a non-linear fashion to a change in the input characteristics.

\section{Nitrite effect on the P-uptake rate of the SBR and MBR sludge}

In this section, a selection of the results obtained from the batch tests performed with the SBR and the MBR sludges are presented. First, the aerobic P-uptake results are given and thereafter the anoxic P-uptake results with nitrite and nitrate as electron acceptor.

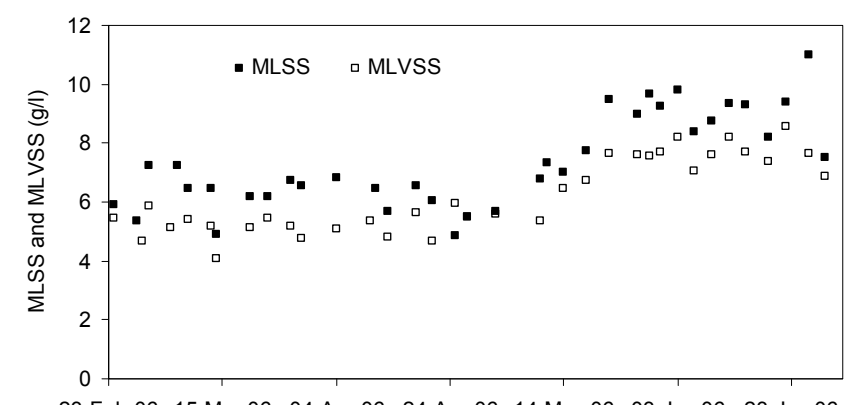

23-Feb-06 15-Mar-06 04-Apr-06 24-Apr-06 14-May-06 03-Jun-06 23-Jun-06

Figure 6

The MLSS and MLVSS profiles in the MBR. The line indicates the gradual increase in the sludge concentration parallel to an increase in the influent wastewater concentration (see the text).
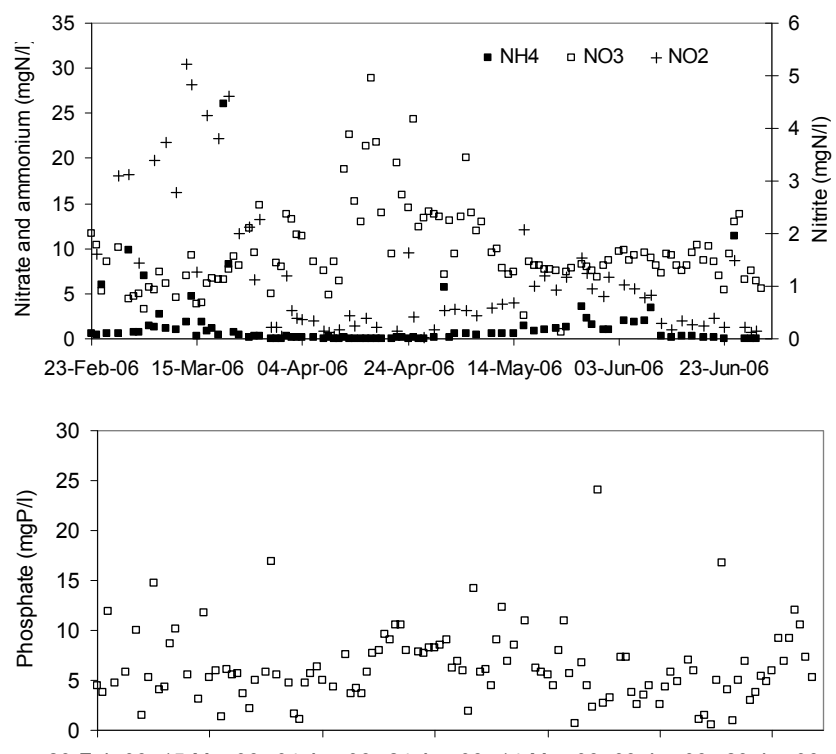

23-Feb-06 15-Mar-06 04-Apr-06 24-Apr-06 14-May-06 03-Jun-06 23-Jun-06

Figure 7

The effluent quality of the MBR: nitrogen (top) phosphate (bottom)

\section{Nitrite effect on the aerobic phosphate uptake rate (PUR)}

The aerobic P-uptake results under different initial nitrite concentrations are presented in Fig. 8 (top) and Fig. 8 (bottom) for the SBR and MBR sludges respectively. In total 3 tests are shown per sludge sample. These tests correspond to 0,5 and $10 \mathrm{mg} \mathrm{NO}_{2}$ $\mathrm{N} / \ell$ additions at the beginning of the aerobic P-uptake phase (as indicated by the arrow in Fig. 8). The resulting P-uptake profiles from these additions are marked by different symbols corresponding to each initial $\mathrm{NO}_{2}-\mathrm{N}$ concentration (see the legend of Fig. 8). The decreasing nitrite concentration profiles due to the activity of nitrite oxidising bacteria (NOB) during these aerobic tests were also plotted indicating the exposure concentration and duration of PAO to nitrite throughout the aerobic P-uptake phase.

The P-release and P-uptake profiles obtained in this study (e.g. see Fig. 8) indicate a typical polyphosphate-accumulating metabolism (PAM). During the anaerobic phase and in the presence of external VFA such as acetate, phosphate release occurs to generate the energy necessary to take up the external VFA and store internally in the form of PHA. During this phase inter- 

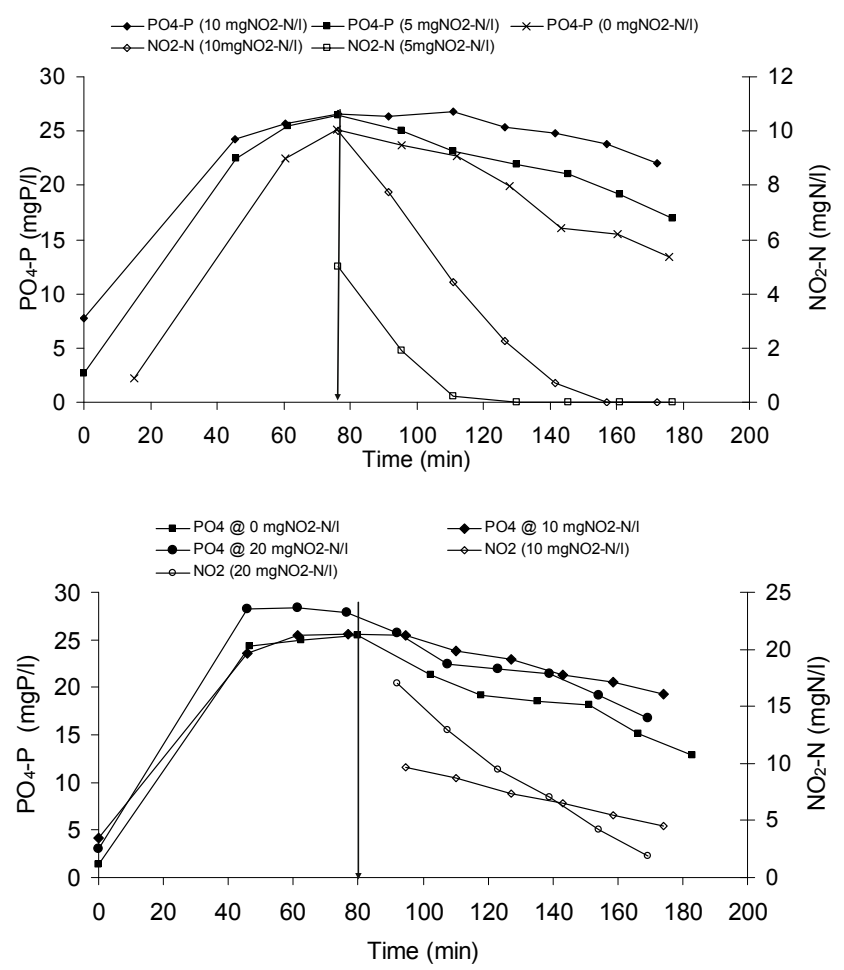

Figure 8

The aerobic P-uptake vs. nitrite: for SBR sludge (top) and MBR sludge (bottom). The arrow indicates the end of the P-release and the start of the P-uptake

nal glycogen is also expected to be used for balancing reducing equivalents (Mino et al., 1987; Smolders et al., 1995; Schuler and Jenkins, 2003). In the following aerobic or anoxic phase, the internally stored PHA is used both as carbon and energy source nitrate) for P-uptake, but also for restoring the glycogen pool and the biomass growth (Smolders et al., 1995).

As shown in Fig. 8, in the first 75 min of the batch test, which is anaerobic, the phosphate release took place. The phosphorus release rate was observed to be high in the beginning (e.g. between 0 and $40 \mathrm{~min}$ ) thanks to the sufficient amount of acetate present externally and to the internal polyphosphate and glycogen pools present in the PAO organisms. The phosphate release later on slowed down until coming to a halt probably due to the depletion of the external carbon source. This P-release trend was observed in all of the 6 tests shown in Fig. 8 for the SBR and the MBR sludge.

At the end of the P-release phase, the aerobic P-uptake commences as soon as the aeration is switched on as indicated by the arrow in Fig. 8. One observes that the P-uptake rate is significantly slower than the P-release rate (also for the reference tests, i.e. with zero nitrite addition). For the tests with the SBR sludge, one can clearly observe that the aerobic P-uptake was affected by the presence of nitrite (see Fig. 8 (top)). For example, when the initial nitrite concentration was $5 \mathrm{mg} \mathrm{NO}-\mathrm{N} / \ell$, the aerobic ence P-uptake rate without nitrite addition. Further, the aerobic P-uptake was found to stop completely at $10 \mathrm{mg} \mathrm{NO}-\mathrm{N} / \ell$ and it was resumed in the same batch test only when the nitrite level had been reduced down to about $4 \mathrm{mg} \mathrm{NO}_{2}-\mathrm{N} / \ell$ in the reactor by the nitrite oxidising bacteria. From this point onward, the aerobic P-uptake proceeded at $50 \%$ of the reference aerobic P-uptake rate (the calculation of degree of inhibition presented below). (oxidative phosphorylation using electron acceptor as oxygen or $\mathrm{P}$-uptake rate was reduced by around $30 \%$ compared to the refer-

This implies that the inhibitory effect of nitrite is reversible since with the decreasing nitrite concentration in the medium the P-uptake activity was restored again, albeit slowly. The latter, i.e. the slow P-uptake recovery, indicates that PAOs did not recover fully from the inhibitory effect of nitrite.

In the case of MBR sludge, the nitrite was observed to affect the aerobic P-uptake as well albeit at a smaller magnitude. For example, the aerobic P-uptake did not completely cease at $10 \mathrm{mg}$ $\mathrm{NO}_{2}-\mathrm{N} / \ell$ but was reduced by $63 \%$ of the reference P-uptake rate of the MBR (Fig. 8 (bottom)). A more detailed comparison of the aerobic P-uptake rate of the MBR and the SBR sludge is given in the Discussion.

\section{Nitrite effect on the anoxic phosphate uptake rate (PUR)}

Typical results from the anoxic P-uptake tests are shown in Fig. 9 for the SBR and the MBR biomass. Similar to the tests presented above, the first $75 \mathrm{~min}$ of the tests was the anaerobic P-release phase, while the subsequent phase for the anoxic P-uptake either consisted of the nitrite (top of the figure) or nitrate (bottom of the figure) as indicated by the arrows.

One observes that biomass from both systems was able to use nitrite and nitrate as electron acceptor and to perform the typical polyphosphate-accumulating metabolism (PAM) (Schuler and Jenkins, 2003). Furthermore, within the studied range and up to $25 \mathrm{mg} \mathrm{NO}-\mathrm{N} / \ell$, no inhibitory effect of nitrite could be observed on the anoxic P-uptake activity of either SBR or MBR sludge. Since these results were obtained under $\mathrm{pH}-$ controlled tests, it confirms that elevated nitrite concentrations may not pose significant inhibitory effects on the anoxic phosphate uptake. This is in contrast to the results of Meinhold et al. (1999) and expectation of Saito et al. (2004) but is in line with the results of Ahn et al. (2001) and Hu et al. (2003) who found as well that at high nitrite levels PAOs are still able to show anoxic P-uptake activity.

Comparison of the anoxic P-uptake profiles for the SBR biomass shows that the P-uptake with nitrite appears to proceed faster than the P-uptake with nitrate as electron acceptor. For the MBR biomass, on the contrary, no significant difference can be observed between the anoxic P-uptake rates with nitrite and nitrate. A detailed comparison of the P-uptake rates with these different electron acceptors is given in the discussion.

\section{Discussion}

\section{The calculation of the P-uptake rate}

To quantify the extent of nitrite inhibition of the P-uptake rate, one can calculate and compare the P-uptake rate obtained from exposing the biomass to different levels of nitrite. However, one needs to exercise caution when calculating the P-uptake rate as the P-uptake process is an inherently non-linear one since it depends on several other processes taking place in the cell metabolism, e.g. the degradation rate of the internal organic storage polymers $\left(\mathrm{X}_{\mathrm{PHA}}\right)$ as well as the saturation of the build-up of the polyphosphate pool $\left(\mathrm{X}_{\mathrm{pp}}\right)$. For example, ASM2d model formulates the aerobic P-uptake process (the anoxic P-uptake rate is essentially the same but with nitrate as electron acceptor instead of oxygen) as follows:

$$
\begin{aligned}
P U R_{O 2}= & q_{P P} \cdot \frac{S_{O 2}}{S_{O 2}+K_{O 2}} \cdot \frac{S_{P O 4}}{S_{P O 4}+K_{P S}} \\
& \cdot \frac{X_{P H A} / X_{P A O}}{X_{P H A} / X_{P A O}+K_{P H A}} \cdot \frac{K_{M A X}-X_{P P} / X_{P A O}}{K_{I P P}+K_{M A X}-X_{P H A} / X_{P A O}} \cdot X_{P A O}
\end{aligned}
$$



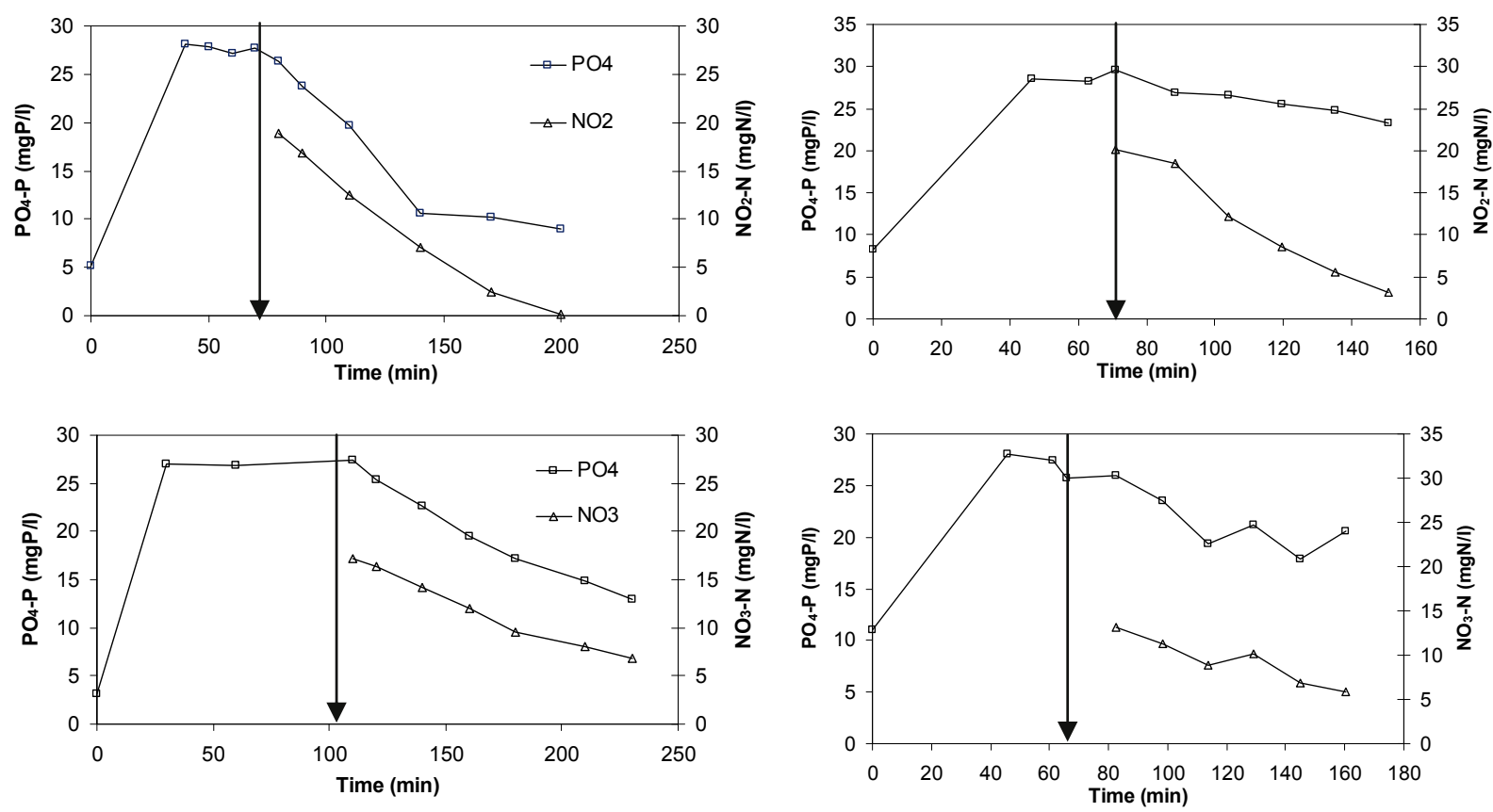

Figure 9

Anoxic P-uptake with $\mathrm{NO}_{2}$ (top) and $\mathrm{NO}_{3}$ (bottom) as electron acceptor:

SBR biomass (left) and MBR biomass (right). The arrows indicate the start of the P-uptake phase.

where:

$P U R_{O_{2}}$ is the aerobic P-uptake rate

$q_{P P}$ stands for the rate constant of P-storage

$K_{O 2}$ and $K_{P S}$ are the saturation coefficients for oxygen and for orthophosphate storage respectively

$S_{\mathrm{O}_{2}}$ and $S_{\mathrm{PO} 4}$ are the oxygen and orthophosphate concentration in the bulk respectively

$X_{P H A}$ and $X_{P P}$

$X_{P A O}$ are the intracellular organic storage products, intracellular polyphosphate storage and concentration of PAOs respectively

$K_{P H A}$ is the saturation coefficient for PHA

$K_{M A X}$ and $K_{I P P}$ are the maximum ratio of $\mathrm{X}_{\mathrm{PP}} / \mathrm{X}_{\mathrm{PAO}}$ (the maximum ratio for polyphosphate storage in the cell) and inhibition coefficient for $\mathrm{X}_{\mathrm{PP}}$ storage (Henze et al., 2000).

Important to note is that while other models have formulated different mechanisms to describe the P-uptake process, the nonlinear nature of the process remains similar (Smolders et al., 1995; Meijer et al., 2001). This non-linear process can be assumed to proceed linearly under the following assumptions:

- Sufficiently high level of $\mathrm{X}_{\mathrm{PHA}}$, e.g. $\mathrm{X}_{\mathrm{PHA}} / \mathrm{X}_{\mathrm{PAO}}$ is higher than 0.01 .

- $\mathrm{X}_{\mathrm{PP}}$ is much lower than the $\mathrm{K}_{\mathrm{MAX},}$ e.g. $\mathrm{X}_{\mathrm{PP}} / \mathrm{X}_{\mathrm{PAO}}$ is lower than 0.34 .

- Sufficiently high level of orthophosphate $\left(\mathrm{S}_{\mathrm{PO} 4}\right)$ and electron acceptor (e.g. $\mathrm{S}_{\mathrm{O} 2}$ ).

Under these assumptions, the saturation and inhibition terms of Eq. (1) will be rendered to approximately 1, which means that the PUR will be driven close to its maximum under the given conditions. Under such conditions, the PUR can be experimentally calculated as the slope of the observed P-uptake.

Concerning the batch experiments performed in this study, we assumed that the first hour of the P-uptake experiment is likely to meet the above-mentioned assumptions and therefore

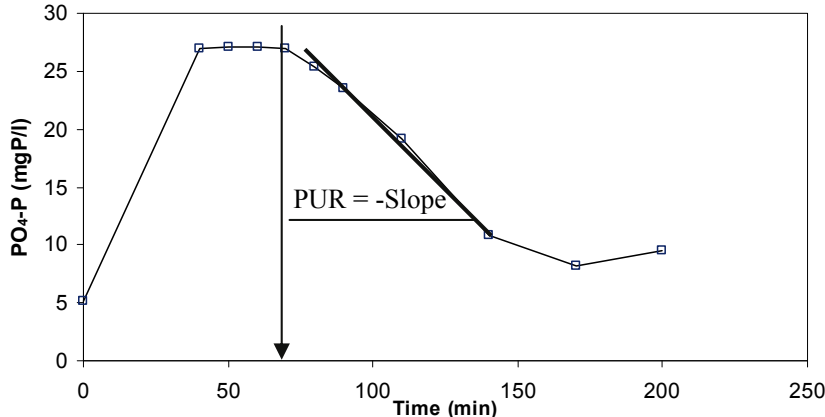

Figure 10

Illustration of the calculation of the P-uptake rate from the $P$-uptake profiles obtained from the batch tests. The arrow indicates the beginning of the P-uptake.

to proceed independent of limitations/inhibitions. Hence, we approximated the PUR from the slope of the measured $\mathrm{PO}_{4}-\mathrm{P}$ profile in the first hour of the P-uptake experiment. This is illustrated in Fig. 10 for one P-uptake profile obtained from one of the anoxic batch tests in Fig. 10. Although this approach is an approximation in its nature, it is still expected to provide a means to quantify the effect of nitrite on the P-uptake.

\section{Nitrite inhibition of the aerobic P-uptake}

The degree of nitrite inhibition was calculated on the basis of the observed aerobic P-uptake rates obtained under the different nitrite concentrations of Fig. 8. The results are given in Table 1 both for the SBR and the MBR biomass.

The PUR(\%) is calculated as $\left(\frac{P U R_{N O 2}}{P U R_{2}} \times 100\right)$, which is the percent ratio of the observed P-uptake rate at a certain nitrite level, $\mathrm{PUR}_{\mathrm{NO} 2}$, to the reference $\mathrm{P}$-uptake rate, $\mathrm{PUR}_{0}$, obtained under zero nitrite concentration. The degree of inhibition is then calculated as $\left(\frac{P U R_{0}-P U R_{N O 2}}{P U R_{0}}\right)$. The degree of inhibition may take a value 
of between 0 and 1 , corresponding to no and severe inhibition respectively.

Table 1 indicates that the degree of nitrite inhibition of the PAOs from the SBR biomass is considerably higher than that of the PAOs in the MBR biomass within the experimentation period. This shows that the PAOs from the SBR were more vulnerable to nitrite exposure. Long-term effluent monitoring of both systems shows that the nitrite concentration sporadically reaches up to 1.5 and $2.5 \mathrm{mg} \mathrm{NO}-\mathrm{N} / \ell$ in the effluent of both systems (Fig. 5 and Fig. 7). This means that both systems were sporadically exposed to nitrite, hence one expects that polyphosphate accumulating organisms present in both systems would be adapted to nitrite to a similar degree, which apparently was not the case.

Alternatively, the underlying reason could be related to the different performance of these two systems with respect to nitrification, denitrification and P-removal. One may expect that different organisms or perhaps, using the argument of Schuler and Jenkins (2003), a different polyphosphate-accumulating metabolism (PAM) could be responsible for the observed difference in the response of the SBR and the MBR systems to nitrite exposure. Quantitative molecular techniques such as FISH-MAR are of course needed to support these speculative arguments (Seviour et al., 2003), which is beyond the scope of the current contribution.

\section{Electron acceptor preference of PAOs}

A summary of the phosphate uptake rates obtained under three different redox conditions, namely with presence of oxygen, nitrate and nitrite, are shown for the SBR biomass in Table 2. A comparison of the phosphate uptake rates with these different electron acceptors shows that the PUR obtained with nitrite was $60 \%$ faster than the PUR obtained with nitrate. It also follows that the nitrite uptake rate, as referenced to the electron content of nitrate, i.e. $3 / 5 * \mathrm{~N}_{\mathrm{O} 2} \mathrm{UR}$, was around $60 \%$ higher than the nitrate uptake rate $\left(\mathrm{NUR}_{\mathrm{NO} 3}\right)$. This suggests that the anoxic PUR was limited by the nitrate uptake rate. In short, for this particular biomass the anoxic P-uptake was faster with nitrite than with nitrate.

When compared to the aerobic PUR, the reduction factor for PUR with nitrate and nitrite was found to be 0.5 and 0.8 respectively. The fact that different $\mathrm{P}$-uptake rates under different electron acceptor conditions were observed suggests that the P-uptake rate is different under different e-acceptor conditions

\section{TABLE 1}

Degree of nitrite inhibition of the aerobic P-uptake

\begin{tabular}{|c|c|c|c|c|c|c|}
\hline Initial $\mathrm{NO}_{2}-\mathbf{N}$ & \multicolumn{2}{|c|}{ PUR(mg P/l-h) } & \multicolumn{2}{c|}{ PUR (\%) } & \multicolumn{2}{c|}{$\begin{array}{c}\text { Degree of } \\
\text { inhibition }\end{array}$} \\
\hline $\mathbf{m g ~ N O}_{2}$-N/l & SBR & MBR & SBR & MBR & SBR & MBR \\
\hline 0 & $8.1 \pm 1.2$ & $6.5 \pm 1.0$ & 100 & 100 & 0 & 0 \\
\hline 5 & $5.5 \pm 0.5$ & $5.8 \pm 1.1$ & 71 & 86 & 0.29 & 0.14 \\
\hline 10 & $2.7 \pm 0.9$ & $4.1 \pm 0.5$ & 35 & 63 & 0.65 & 0.37 \\
\hline
\end{tabular}

or that different fractions of PAOs are active under different electron acceptor conditions.

A classic question related to such results is whether one type of facultative PAO is able to perform polyphosphateaccumulating metabolism with oxygen, nitrate and nitrite (one organism, all functions) or rather that different types of PAOs specialise in performing different types of phosphorus uptake metabolism (different organisms, different functions). To address this question, we have performed dedicated tests with mixtures of nitrite and nitrate as electron acceptors.

The results, shown in Fig. 11 provide several insights. First, they show that both electron acceptors were simultaneously utilised while the phosphate was being taken up and stored by the PAOs. Second, the nitrite uptake rate was faster than the nitrate uptake rate which explains the fact that no nitrite build-up was observed during nitrate-denitrification. Moreover, the observed P-uptake rate was found to be around $3.5 \mathrm{mg} \mathrm{P} / \mathrm{g} \mathrm{SS}-\mathrm{h}$ in the presence of both nitrite and nitrate. This rate is higher than the average anoxic P-uptake rate with nitrate alone (see Table 2). This implies that the PUR corresponding to the presence of nitrite and nitrate may be due to a cumulative activity of PAOs performing nitrite and nitrate metabolisms. This in turn suggests that there might be different PAO types performing different functions in this particular SBR sludge.

\section{Nitrite inhibition threshold: Summary}

A summary of the results obtained so far in several studies about the effect of nitrite on the phosphate-accumulating organisms'
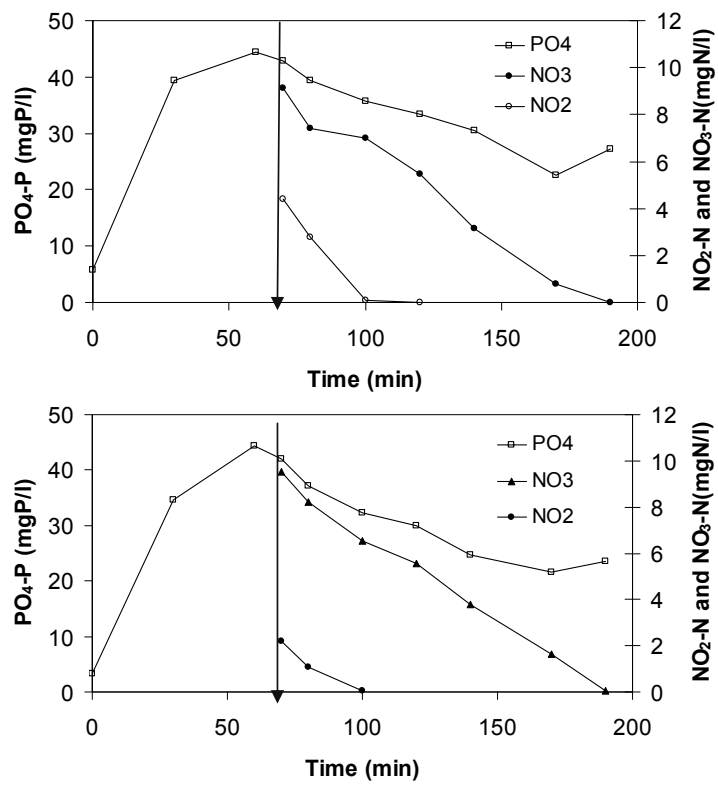

Figure 11

Anoxic phosphate uptake with mixture of nitrate and nitrite as electron acceptor: $12 \mathrm{mg} \mathrm{NO}_{3}-\mathrm{N} / \mathrm{\ell}+5 \mathrm{mg} \mathrm{NO}{ }_{2}-\mathrm{N} / \mathrm{\ell}$ (top) $12 \mathrm{mg} \mathrm{NO}{ }_{3}-\mathrm{N} / \ell+2.5 \mathrm{mg} \mathrm{NO}_{2}-\mathrm{N} / \ell$ ( bottom)

TABLE 2

P-uptake rates under different electron acceptor for the SBR biomass

\begin{tabular}{|l|l|l|l|l|l|}
\hline & $\mathbf{O}_{2}$ & $\mathbf{N O}_{2}-\mathbf{N}$ & $\mathbf{N O}_{3}-\mathbf{N}$ & $\eta_{\text {PUR NO2 }}{ }^{1}$ & $\eta_{\text {PUR }_{\text {NO3 }}}{ }^{1}$ \\
\hline${ }^{2}$ Specific PUR (mg P/g SS-h) & $3.9 \pm 0.4$ & $3.1 \pm 0.4$ & $2.0 \pm 0.4$ & 0.80 & 0.52 \\
\hline${ }^{2}$ Specific NUR (mg N/g SS-h) & - & $2.2 \pm 0.1$ & $1.4 \pm 0.1$ & & \\
\hline
\end{tabular}

Anoxic reduction factor for aerobic PUR under anoxic conditions, i.e. for $\mathrm{NO}_{2}$ and $\mathrm{NO}_{3}$ respectively

${ }^{2}$ Each rate is determined as the average of 4 batch tests 


\begin{tabular}{|c|c|c|c|c|}
\hline \multicolumn{5}{|c|}{$\begin{array}{r}\text { TABLE } 3 \\
\text { Overview of the response of PAO to nitrite under }\end{array}$} \\
\hline & \multirow[t]{2}{*}{ Operation strategy } & \multirow[t]{2}{*}{ Type of reactor/wastewater } & \multicolumn{2}{|c|}{ Inhibition level of nitrite } \\
\hline & & & Aerobic P-uptake & Anoxic P-uptake \\
\hline $\begin{array}{l}\text { Meinhold } \\
\text { et al. }\end{array}$ & Anoxic/aerobic & $\begin{array}{l}\text { Pilot-scale BPR plant fed with real } \\
\text { wastewater }\end{array}$ & $10-15 \mathrm{mg} \mathrm{NO}_{2}-\mathrm{N} / \ell$ & $5-8 \mathrm{mg} \mathrm{NO}_{2}-\mathrm{N} / \ell$ \\
\hline Ahn et al. & Anaerobic/aerobic & $\begin{array}{l}\text { Lab-scale SBR fed with real } \\
\text { wastewater }\end{array}$ & Not tested & $\begin{array}{l}\text { No inhibition } \\
\text { (up to } 40 \mathrm{mg} \mathrm{N} / \ell \text { ) }\end{array}$ \\
\hline Lee et al. & $\begin{array}{l}\text { Anaerobic/aerobic/ } \\
\text { anoxic /aerobic }\end{array}$ & $\begin{array}{l}\text { Lab-scale SBR fed with synthetic } \\
\text { wastewater, BNPR plant }\end{array}$ & Not tested & $\begin{array}{l}\text { No inhibition } \\
\text { (up to } 10 \mathrm{mg} \mathrm{N} / \ell \text { ) }\end{array}$ \\
\hline Hu et al. & Anaerobic/ anoxic & $\begin{array}{l}\text { Lab-scale SBR fed with synthetic } \\
\text { wastewater, BPR plant }\end{array}$ & Not tested & $\begin{array}{l}\text { No inhibition } \\
\text { (up to } 35 \mathrm{mg} \mathrm{N} / \ell \text { ) }\end{array}$ \\
\hline $\begin{array}{l}\text { Saito et } \\
\text { al. }\end{array}$ & $\begin{array}{l}\text { Anaerobic/ anoxic/ } \\
\text { aerobic }\end{array}$ & $\begin{array}{l}\text { Lab-scale SBR fed with real } \\
\text { wastewater, BPR }\end{array}$ & $\begin{array}{l}2 \mathrm{mg} \mathrm{NO}-\mathrm{N} / \ell \text { partial; } \\
6 \mathrm{mg} \mathrm{NO}_{2}-\mathrm{N} / \ell \text { complete inhibition }\end{array}$ & $12 \mathrm{mg} \mathrm{NO}-\mathrm{N} / \ell$ \\
\hline $\begin{array}{l}\text { Yoshida } \\
\text { et al. }\end{array}$ & $\begin{array}{l}\text { Anaerobic/aerobic } \\
\text { and Anaerobic/ } \\
\text { anoxic }\end{array}$ & $\begin{array}{l}\text { Lab-scale SBR fed with } \\
\text { synthetic wastewater, BPR }\end{array}$ & $\begin{array}{l}1 \mathrm{mg} \mathrm{NO}_{2}-\mathrm{N} / \ell \text { for } \mathrm{A} / \mathrm{O} \\
3 \mathrm{mg} \mathrm{NO}_{2}-\mathrm{N} / \ell \text { for } \mathrm{A} 2 \mathrm{O} \text { sludge }\end{array}$ & Not tested \\
\hline $\begin{array}{l}\text { Soejima } \\
\text { et al. }\end{array}$ & $\begin{array}{l}\text { Anaerobic/ aerobic/ } \\
\text { anoxic/SBR }\end{array}$ & $\begin{array}{l}\text { Lab-scale SBR fed with synthetic } \\
\text { wastewater, BNPR plant }\end{array}$ & $\begin{array}{l}\text { Inhibition reported but not quanti- } \\
\text { fied }\end{array}$ & Not tested \\
\hline $\begin{array}{l}\text { This } \\
\text { study }\end{array}$ & $\begin{array}{l}\text { Anaerobic/ aerobic/ } \\
\text { anoxic/ aerobic SBR } \\
\text { and Anaerobic/ } \\
\text { anoxic/ aerobic MBR }\end{array}$ & $\begin{array}{l}\text { Pilot-scale SBR and MBR fed } \\
\text { with synthetic wastewater: BNPR } \\
\text { plant }\end{array}$ & $\begin{array}{l}5 \mathrm{mg} \mathrm{NO}-\mathrm{N} / \ell \text { SBR sludge; } \\
10 \mathrm{mg} \mathrm{NO}_{2}-\mathrm{N} / \ell \text { MBR sludge }\end{array}$ & $\begin{array}{l}\text { No inhibition } \\
\text { (up to } 20 \mathrm{mg} \mathrm{NO}-\mathrm{N} / \ell \text { ) }\end{array}$ \\
\hline
\end{tabular}

activity (both aerobic and anoxic) is given in Table 3. The majority of the studies showed that nitrite is inhibitory to the aerobic P-uptake activity. Further, some denitrifying PAOs are also able to utilise nitrite as electron acceptor for the anoxic P-uptake both at high nitrite level and at considerable rate.

That said, however, the results also showed a wide variation in the inhibitory threshold values. These wide variations may result from the history of biomass used in these abovementioned studies. The 'history' includes the particular environmental conditions the biomass has been exposed to prior to analysis in the batch tests. Indeed, there are many interacting factors including the operational strategy, type of wastewater, type of reactor, dynamic operational disturbances as well as competition/interaction with other microbial populations that may influence the response of PAO to the nitrite exposure. These combined interactions will affect the physiology of the PAO enriched in a particular system. To this end, it is suggested to use standard batch P-uptake tests to assess the nitrite threshold for a particular PAO system. From a theoretical understanding point of view, research at physiological and metabolic level of the PAOs combined with a detailed process analysis of the history of the system is expected to help uncover the mechanism of nitrite inhibition.

\section{Implications to operation of alternating EBPR systems: Proactive approach to solve nitrite inhibition}

In biological systems performing simultaneous nitrogen and phosphorus removal, such as the case of the SBR and MBR systems of this study, it is well-known that phosphate removal can become unstable and lose its efficiency because of the direct competition for substrate between PAOs and normal denitrifying heterotrophs, when nitrate reaches the anaerobic compartment (Manning and Irving, 1985; Wilderer et al., 2001). However, the instability of the system may also be caused by the accumulation of nitrite in the aerobic phase, which may result from a low oxygen concentration in the aerobic phases, low aerobic SRT and/ or low temperatures that strongly affect the activity of nitrite oxidisers (Wiesmann, 1994).

To resolve the nitrite inhibition in EBPR systems exposed to nitrite build-up, the obvious approach is to prevent the buildup of nitrite by complete nitrification and denitrification. Alternatively, we suggest a pro-active solution in which the aerobic P-uptake phase is replaced with the anoxic P-uptake phase using nitrite as e-acceptor. This pro-active approach rests on the assumption that anoxic PAOs able to use nitrite as e-acceptor can be enriched to sufficiently high extent to provide high observed P-uptake rates.

For this assumption, this study showed that PAOs are capable of using nitrite as electron acceptor at a rate equal to at least $60 \%$ (if not more) of the aerobic P-uptake rate (see above the SBR biomass). The results of this study also showed that some particular DPAOs may prefer nitrite over nitrate (e.g. because of selective enrichment of nitrite reducing PAOs in a particular system configuration). Hence this assumption is met.

To implement such a process in full-scale, one needs to develop an appropriate anoxic EBPR configuration/technology. A good starting point would be to look into modifying the denitrifying phosphorus accumulating systems to use only nitrite as electron acceptor instead of using nitrate that is commonly used in practice (see e.g. Kuba et al., 1996). This configuration can be coupled to nitrogen removal via the nitrite route (Van Benthum et al., 1998; Van Dongen et al., 2001; Antileo et al., 2003) thereby resulting in a potentially novel nitrogen- and phosphorus-removal system configuration.

\section{Anoxic EBPR operated with nitrite vs. nitrate}

The advantage of developing a nitrite-reducing DPAO system is that more nitrite can be removed on mass basis per unit mass of PHA oxidised by DPAOs during the anoxic P-uptake phase. In this way, theoretically more nitrogen removal can be achieved using anoxic DPAO activity with nitrite, theoretically $3 / 5$ times more than what can be achieved with a DPAO system using nitrate. In such a configuration, however, one again needs to 
account for the possible proliferation of denitrifying glycogen accumulating organisms (GAOs), which may prevent the system to achieve nitrogen and phosphorus removal over nitrite. Such an interference of GAO was shown in Zeng et al. (2003) for a particular lab-scale reactor configuration. From a process configuration and operation point of view, one also needs to overcome the challenges of maintaining a stable partial nitrification process (i.e. only ammonia conversion to nitrite), which is only possible under a certain reactor configuration, e.g. high temperature, high $\mathrm{pH}$, bicarbonate limitation, oxygen limitation and the like. Overall we believe that designing and operating phosphate uptake phase (PUR) under nitrite anoxic conditions could be a very valuable option for P-removal from nutrient-rich streams such as supernatants from sludge thickeners and digesters.

Moreover granular activated sludge technology focusing on performing simultaneous nitrification, denitrification and phosphorus removal, which currently considers only oxygen and nitrate as electron acceptor for PAOs, may also benefit from including nitrite in the system optimisation (see e.g. de Kreuk et al., 2005). These theoretically possible configurations naturally require experimental evaluation, but in principle such an approach should offer an efficient solution to the inhibitory effect of nitrite on aerobic P-uptake.

\section{Modelling the nitrite effect}

As mentioned earlier, current deterministic models describing the behaviour of EBPR systems ignore two important influences of nitrite on the activity of PAOs:

- The inhibitory effect of nitrite on the aerobic P-uptake

- Nitrite as a plausible electron acceptor for denitrifying PAO activity.

These assumptions are likely to hold for many EBPR systems where there is no nitrite build- up. However, for systems with nitrite build-up such models are expected to fail and will require extension. For such an extension, the above-mentioned fundamental research will be invaluable as it will allow developing a sound mechanistic structure for the nitrite- inhibition mechanism. Lacking that, we propose the following two extensions based on the empirical observations obtained thus far (see Table 3).

\section{Modelling nitrite inhibition of aerobic P-uptake:}

A convenient and simple way of modelling the reversible inhibitory effect of nitrite would be to use a similar function as the one describing the inhibitory effect of oxygen on the denitrifying activity of heterotrophic organisms, i.e. using a switch function, in the form of $\mathrm{K}_{\mathrm{INO} 2} /\left(\mathrm{S}_{\mathrm{NO} 2}+\mathrm{K}_{\mathrm{INO} 2}\right)$, where $\mathrm{K}_{\mathrm{INO} 2}$ stands for inhibition concentration of nitrite. Therefore, the rate equation of P-uptake in ASM2d may become as follows:

$$
\begin{aligned}
P U R_{O 2}= & q_{P P} \cdot \frac{S_{O 2}}{S_{O 2}+K_{O 2}} \cdot \frac{S_{P O 4}}{S_{P O 4}+K_{P S}} \cdot \frac{K_{I N O 2}}{S_{N O 2}+K_{I N O 2}} \\
& \cdot \frac{X_{P H A} / X_{P A O}}{X_{P H A} / X_{P A O}+K_{P H A}} \cdot \frac{K_{M A X}-X_{P P} / X_{P A O}}{K_{I P P}+K_{M A X}-X_{P H A} / X_{P A O}} \cdot X_{P A O}
\end{aligned}
$$

As mentioned earlier, the $\mathrm{K}_{\mathrm{INO} 2}$ appears to vary from system to system and therefore needs experimental determination or calibration from inhibition tests. As our data is not sufficient for reliable parameter estimation (it is a non-linear process), we don't present an estimate for $\mathrm{K}_{\mathrm{INO} 2}$. However, one may state that the lower bound for this estimate seems to be around $5 \mathrm{mg} \mathrm{NO}_{2} / \ell$ and $10 \mathrm{mg} \mathrm{NO}-\mathrm{N} / \ell$ for the SBR and the MBR biomass respectively. Important to note is that the nitrite inhibition coefficient is likely to be $\mathrm{pH}$ dependent as the previous nitrite inhibition studies on other bacteria have confirmed that free nitrous acid $\left(\mathrm{HNO}_{2}\right)$ is the true inhibitory compound.

\section{Modelling anoxic activity of denitrifying PAOs}

There are two possible pathways for modelling denitrification, one assumes a sequential reduction of nitrate to nitrite and then to nitrogen gas, i.e. $\mathrm{NO}_{3} \rightarrow \mathrm{NO}_{2} \rightarrow 1 / 2 \mathrm{~N}_{2}$. Another plausible pathway is parallel and independent reduction of nitrate and nitrite all the way down to nitrogen gas, i.e. $\mathrm{NO}_{3} \rightarrow 1 / 2 \mathrm{~N}_{2}$ and $\mathrm{NO}_{2} \rightarrow 1 / 2 \mathrm{~N}_{2}$ (Sin et al., 2006a).

Our experimental results showed that nitrite reduction by PAOs was faster than nitrate reduction. This phenomenon can be described by both pathways, which means one cannot rule out one pathway over the other based on these empirical results. However, from a modelling perspective, opting for the sequential reduction of nitrate allows to describe more than one particular behaviour of a system, e.g. both nitrite build-up and faster nitrite reduction behaviours can be modelled by appropriate manipulation of the rate parameters of the $1^{\text {st }}$ and the $2^{\text {nd }}$ steps (see Eq. (3) and Eq.(4)). Hence, we suggest the adoption of sequential reduction of nitrate as the model structure for the denitrifying PAOs, until evidence is provided that another structure is needed. The rate equations for nitrate and nitrite reduction processes of ASM2d then become as follows:

$$
\begin{aligned}
P U R_{N O 3}= & q_{P P} \cdot \eta_{N O 3} \frac{K_{O 2}}{S_{O 2}+K_{O 2}} \frac{S_{P O 4}}{S_{P O 4}+K_{P S}} \cdot \frac{S_{N O 3}}{S_{N O 3}+K_{N O 3}} \cdot \frac{S_{N O 3}}{S_{N O 3}+S_{N O 2}} \\
& \cdot \frac{X_{P H A} / X_{P A O}}{X_{P H A} / X_{P A O}+K_{P H A}} \cdot \frac{K_{M A X}-X_{P P} / X_{P A O}}{K_{I P P}+K_{M A X}-X_{P H A} / X_{P A O}} \cdot X_{P A O} \\
P U R_{N O 2}= & q_{P P} \cdot \eta_{N O 2} \frac{K_{O 2}}{S_{O 2}+K_{O 2}} \frac{S_{P O 4}}{S_{P O 4}+K_{P S}} \cdot \frac{S_{N O 2}}{S_{N O 2}+K_{N O 2}} \cdot \frac{S_{N O 2}}{S_{N O 2}+S_{N O 3}} \\
& \cdot \frac{X_{P H A} / X_{P A O}}{X_{P H A} / X_{P A O}+K_{P H A}} \cdot \frac{K_{M A X}-X_{P P} / X_{P A O}}{K_{I P P}+K_{M A X}-X_{P H A} / X_{P A O}} \cdot X_{P A O}
\end{aligned}
$$

In these equations, the competition between electron acceptors is not included, but in case this would be needed, it can be easily described following the concept of substrate competition already used elsewhere in ASM2d.

It is clear that with the introduction of nitrite, the model structure of ASM2d becomes even more complex, i.e. the number of parameters increases significantly. In a way, it becomes more expensive to apply such model, since it requires knowledge/ information about these additional parameters. However, we believe that such an extension is essential if not a must for proper description of simultaneous nitrogen- and phosphorus-removing systems characterised by significant nitrite build-up.

\section{Conclusions}

In this study, the nitrite effect on the aerobic and anoxic P-uptake activities of PAOs grown in an SBR and an MBR system fed with the same synthetic wastewater was investigated experimentally, using batch phosphate uptake tests.

The nitrite was found to inhibit (reversible) the aerobic P-uptake both in the SBR and the MBR biomass. The inhibitory effect was more pronounced on the SBR biomass than the MBR biomass, where the respective degree of inhibition for each biomass was 0.65 and 0.37 at $10 \mathrm{mg} \mathrm{NO}-\mathrm{N} / \ell$. This difference is 
attributed to a different degree of adaptation of PAOs to the presence of nitrite enriched in these particular SBR and the MBR systems.

For the anoxic P-uptake activities, both the SBR and the MBR biomass were found capable of using nitrite as effectively as nitrate as electron acceptor. Surprisingly for the SBR biomass, the anoxic P-uptake rate with nitrite as the electron acceptor was found to be much higher $(60 \%)$ compared to the rate with nitrate as e-acceptor. This finding suggests that a particular group of PAO organisms that prefers nitrite as electron acceptor was enriched in the SBR system.

In view of modelling EBPR systems, the results of this study require an appropriate extension of the current mechanistic models with aerobic nitrite inhibition and anoxic P-uptake using nitrite as electron acceptor. A possible extension to the ASM2d model has also been suggested.

In view of full-scale EBPR operation, to resolve the nitrite inhibition for the EBPR systems exposed to nitrite build-up, we suggest replacing the aerobic P-uptake phase with an anoxic P-uptake phase using nitrite as electron acceptor. Such a solution could be achieved by combining anaerobic P-release phase/ tanks with a post-denitrification system operated on nitrite route. Such an approach offers promising cost-savings in EBPR systems, which deserves further research.

\section{Acknowledgement}

Peter A Vanrolleghem holds the Canada Research Chair in water quality modelling. Ingmar Nopens is a postdoctoral fellow of the Ghent University Research Fund. Gürkan Sin is an HC Ørsted postdoctoral fellow at the Technical University of Denmark.

\section{References}

AHN J, DAIDOU T, TSUNEDA S and HIRATA A (2001) Metabolic behavior of denitrifying phosphate-accumulating organisms under nitrate and nitrite electron acceptor conditions. J. Biosci. Bioeng. 92 (5) 442-446.

ANTHONISEN AC, LOEHR RC, PRAKASAM TBS and SRINATH EG (1976) Inhibition of nitrification by ammonia and nitrous-acid. J. Water Pollut. Control Fed. 48 (5) 835-852.

ANTILEO C, ROECKEL M and WIESMANN U (2003) High nitrite build-up during nitrification in a rotating disk reactor. Water Environ. Res. 75 (2) 151-162.

BOEIJE G, CORSTANJE R, ROTTIERS A and SCHOWANEK D (1999) Adaptation of the CAS test system and synthetic sewage for biological nutrient removal. Part I: Development of a new synthetic sewage. Chemosphere 38 (4) 699-709.

CASEY TG, WENTZEL MC and EKAMA GA (1999) Filamentous organism bulking in nutrient removal activated sludge systems Paper 9: Review of biochemistry of heterotrophic respiratory metabolism. Water SA 25 (4) 409-424. http://www.wrc.org.za/archives/ watersa\%20archive/1999/October/oct99 p409.pdf

DE KREUK M, HEIJNEN JJ and van LOOSDRECHT MCM (2005) Simultaneous COD, nitrogen, and phosphate removal by aerobic granular sludge. Biotechnol. Bioeng. 90 (6) 761-769.

HU JY, ONG SL, NG WJ, LU F and FAN XJ (2003) A new method for characterizing denitrifying phosphorus removal bacteria by using three different types of electron acceptors. Water Res. 37 (14) 3463-3471.

INSEL G, SIN G, LEE DS, NOPENS I and VANROLLEGHEM PA (2006) A calibration methodology and model-based systems analysis for SBRs removing nutrients under limited aeration conditions. J. Chem. Technol. Biotechnol. 81 (4) 679-687.

JIANG T (2007) Characterization and Modeling of Soluble Microbial Products in Membrane Bioreactors. Ph.D. thesis. Ghent University, Belgium.
KUBA T, VAN LOOSDRECHT MCM and HEIJNEN JJ (1996) Phosphorus and nitrogen removal with minimal COD requirement by integration of denitrifying dephosphatation and nitrification in a two-sludge system. Water Res. 30 (7) 1702-1710.

LEE DS, JEON CO and PARK JM (2001) Biological nitrogen removal with enhanced phosphate uptake in a sequencing batch reactor using single sludge system. Water Res. 35 (16) 3968-3976.

MARTINS AMP, PAGILLA K, HEIJNEN JJ and van LOOSDRECHT MCM (2004), Filamentous bulking sludge - a critical review. Water Res. 38 793-817.

MANNING JF and IRVINE RL (1985) The biological removal of phosphorous in a sequencing batch reactor. J. Water Pollut. Control Fed. 57 87-94.

MEIJER SCF, van LOOSDRECHT MCM and HEIJNEN JJ (2001) Metabolic modelling of full-scale biological nitrogen and phosphorus removing WWTPs. Water Res. 35 (11) 2711-2723.

MEINHOLD J, ARNOLD E and ISAACS S (1999) Effect of nitrite on anoxic phosphate uptake in biological phosphorus removal activated sludge. Water Res. 33 (8) 1871-1883.

MUSVOTO EV, LAKAY MT, CASEY TG, WENTZEL MC and EKAMA GA (1999) Filamentous organism bulking in nutrient removal activated sludge systems - Paper 8: The effect of nitrate and nitrite.Water SA 25 (4) 397-407. http://www.wrc.org.za/archives/ watersa\%20archive/1999/October/oct99_p397.pdf

RAKE JB and EAGON RG (1980) Inhibition, but not uncoupling, of respiratory energy coupling of 3 bacterial species by nitrite. J. Bacteriol. 144 (3) 975-982.

SAITO T, BRDJANOVIC D, and van LOOSDRECHT MCM (2004) Effect of nitrite on phosphate uptake by phosphate accumulating organisms. Water Res. 38 (17) 3760-3768.

SCHULER AJ and JENKINS D (2003) Enhanced biological phosphorus removal from wastewater by biomass with different phosphorus contents. Part I: Experimental results and comparison with metabolic models. Water Environ. Res. 75 (6) 485-498.

SEVIOUR RJ, MINO T and ONUK IM (2003) The microbiology of biological phosphorus removal in activated sludge systems. Fems Microbiol. Rev. 27 (1) 99-127.

SIN G and VANROLLEGHEM PA (2006a) Evolution of an ASM2dlike model structure due to operational changes of an SBR process. Water Sci. Technol. 53 (12) 237-245.

SIN G, VILLEZ K and VANROLLEGHEM PA (2006b) Application of a model-based optimisation methodology for nutrient removing SBRs leads to falsification of the model. Water Sci. Technol. 53 (4-5) 95-103.

SOEJIMA K, OKI K, TERADA A, TSUNEDA $\mathrm{S}$ and HIRATA A.(2006) Effects of acetate and nitrite addition on fraction of denitrifying phosphate-accumulating organisms and nutrient removal efficiency in anaerobic/aerobic/anoxic process. Bioproc. Biosyst. Eng. 29 (5-6) 305-313.

STANDARD METHODS (1998) Standard Methods for the Examination of Water and Wastewater (20th edn.) American Public Health Association (APHA), Washington DC.

VADIVELU VM, KELLER J and YUAN ZG (2006) Effect of free ammonia and free nitrous acid concentration on the anabolic and catabolic processes of an enriched Nitrosomonas culture. Biotechnol. Bioeng. 95 (5) 830-839.

VAN BENTHUM WAJ, DERISSEN BP, van LOOSDRECHT MCM and HEIJNEN JJ (1998) Nitrogen removal using nitrifying biofilm growth and denitrifying suspended growth in a biofilm airlift suspension reactor coupled with a chemostat. Water Res. 32 (7) 2009-2018.

VAN DONGEN U, JETTEN MSM and van LOOSDRECHT MCM (2001) The SHARON $\AA$-Anammox ${ }^{\circledR}$ process for treatment of ammonium rich wastewater. Water Sci. Technol. 44 (1) 153-160.

VAN HULLE SWH, VOLCKE EIP, LÓPEZ JT, DONCKELS B, VAN LOOSDRECHT MCM and VANROLLEGHEM PA (2007) Influence of temperature and $\mathrm{pH}$ on the kinetics of the SHARON nitritation process. J. Chem. Technol. Biotechnol. 82 (5) 471-480.

WIESMANN U (1994) Biological nitrogen removal from wastewater In: Fiechter A (ed.) Advances in Biochemical Engineering/Biotechnology. Vol 5. Springer Verlag, Berlin, Germany. 
WILDERER P, IRVINE RL and GORONSZY MC (2001) Sequencing Batch Reactor Technology. IWA Scientific and Technical Report No. 10. IWA Publishing, London.

YARBROUGH JM, RAKE JB and EAGON RG (1980) Bacterial inhibitory effects of nitrite - inhibition of active-transport, but not of group translocation, and of intracellular enzymes. Appl. Environ. Microbiol. 39 (4) 831-834.

ZENG RJ, LEMAIRE R, YUAN Z and KELLER J (2003) Simultaneous nitrification, denitrification, and phosphorus removal in a lab-scale sequencing batch reactor. Biotechnol. Bioeng. 84 (2) 170-178. 